\title{
Existing Issues of Ride Sharing Company Operation and Sharing Economy in China: Uber Case Analysis
}

\author{
ZHAO Xingyue, SU Qin \\ Xi'an Jiaotong University, Xi'an, China
}

\begin{abstract}
Under the background of the growth of sharing economy, the number of emerging companies increased in the past decade. As emerging companies, the legality and competitions with relevant industries are subject to dispute. This paper analyzes potential issues and causes of these issues in the operation of these companies from business and enterprise perspectives. The article is taking Uber as an example and accordingly presents the solutions and implementations to existing problems of the future. This paper also extends to the current and future situation of sharing economy for Chinese enterprise.
\end{abstract}

Keywords: ride sharing market, the sharing company in China, Uber analysis

\section{Background}

In 2009, Travis Kalanick and Garrett Camp funded Uber to connect passengers with drivers by using smartphone app after experiencing the dilemma of finding a taxi in Paris, whose mission is to connect people that need a reliable ride with people looking to earn money driving their car (Uber, 2019). Two years later, UberCab was officially launched as a private luxury car service in San Francisco. Passengers are able to make reservations by downloading the app and track divers' location on that with the estimated prices based on the time or distances of the rides and passengers are able to use cashless payment (Damodaran, 2014).

However, after UberCab was launched onto the market, it received cease-and-desist letters in operating without the taxi license. Kalanick argued that the company is a provider who connected passengers with drivers, instead of actually operating as a taxi company, and officially changed the name from UberCab to Uber. Until 2015, Uber still was facing a series of resisting from regulators, politicians, and the taxi industry. Uber was banned by some countries and treated as an illegal taxi service. Also, the battles between Uber and public relations become increasingly intense.

Even with all those challenges, Uber reported that it still had two million reservations per day in 2015 (Moon, 2015). At the end of 2015, Uber became a global player, who had more than one million activity drivers in more than 60 countries (Moon, 2015). Uber is trying to launch new services like UberPOOL, driverless car initiative, and UberEATS to diversify their products and maximize market share (Uber, 2019).

ZHAO Xingyue, MBA, State Key Laboratory for Manufacturing Systems Engineering, Xi'an Jiaotong University, Xi'an, China.

SU Qin, Ph.D., professor, State Key Laboratory for Manufacturing Systems Engineering, Xi'an Jiaotong University, Xi'an, China.

Correspondence concerning this article should be addressed to ZHAO Xingyue, School of Management, Xi'an Jiaotong University, West Xianning Road, Xi'an, Shaanxi, China. 


\section{Analysis of Problem and Problem Statement}

The nature of Uber is media of connecting passengers and drivers by Internet app. In the process of development, Uber has been facing some rigorous issues, including the violation of local regulations, battles with the taxi industry, surge pricing policy, and overly aggressive market tactics.

\section{The Violation of Local Regulation}

The initial expansion of Uber was too fast to follow the legal systems and local governmental regulations, which resulted in illegal operations and unfair competitions. The startup rapidly grew with venture investment to spread its business all over the world and attained enough profits to resist laws and regulations. Together with the unclear legality for new things, Uber ignored all the rules based on its strong capital. After a few months of operation, Uber was warned and required to cease all operations due to the lack of taxi licenses by the California Public Utilities Commission and the San Francisco Municipal Transportation Agency (Moon, 2015). Uber reacted to this warning by changing the company name and ignoring the punishment orders. Furthermore, because of the large amount of financing, Uber was able to design the extremely low price with coupons and discounts for customers at the time of entering the market and unfairly competing with competitors. Uber's violation of regulations had invidiously expelled rivals and disrupted the market order.

\section{Battles With the Taxi Industry}

Battles between Uber and taxi companies fully broke out in 2015 because Uber had taken customers from taxi drivers and made them difficult to survive. In the Netherlands and South Korea, for instance, Uber was regarded as illegal car service and would be forbidden. Moreover, strikes and protest against Uber were erupted in some regions and sometimes gone violence. People were not satisfied with the deregulation of Uber, the unfair competitions, hoping it could be regulated and supervised. The rules and regulations of taxi industry require that every single vehicle in operation has to have operation medallions and then allowed to dispatch and pick up passengers on the street. Uber, on the other side, was doing the taxi business without the business license in this industry. Also, it is a complex process to be a taxi driver with a license and medallions, so that the taxi industry was a winner-take-all industry where top drivers could get high payments but lower-level ones were paid few wages. The appearance of Uber completely broke the traditional model of the taxi industry, whose interest was badly damaged (Angrist, Caldwell, \& Hall, 2017). The pre-conditions of Uber drivers are much simpler that almost everyone could be qualified for a smartphone and a vehicle. Therefore, the conflicts between Uber and the taxi industry continuously upgraded were inevitable. Besides the taxi industry, Uber also had other competitors in the market such as limousine and black town car service, and other ride-sharing services such as Lyft and Sidecar (Moon, 2015).

\section{Surge Pricing Policy}

Customers complained about the surge pricing police Uber was using during the rush hours, peak times, and seasonal index; car service would charge several times the normal price (Chen \& Sheldon, 2015). "Surge Pricing" could be 1.5 to 7 times of the normal price in Festivals like New Year's Eve and bad-weather days such as winter snow storms, which dissatisfied the customers that then accused Uber of exploitation. For Uber drivers, they were contract workers and got $80 \%$ or less payment of what passengers paid because Uber Company demanded to collect $20 \%$ to $30 \%$ payment for its commission. Thus drivers were also under a feeling of being exploited. 


\section{Overly Aggressive Market Tactics}

Uber rampantly expanded new markets without considering local laws and regulations, and could not wait to operate after permission. The company was discovered to damage other ride-sharing rivals by black-box operations. What was more, Uber poached drivers from peer companies with inducements of high bonus and incentives, which aggressively enlarged the unfair competitions by unethical business behaviors.

\section{Market Analysis}

\section{Market Strengths}

Under the so-called sharing economy, Uber was able to occupy up to $69 \%$ market share in the United States due to its efficiency and convenience and with strong brand recognition (Iqbal, 2019). The process of the Uber app is simple and friendly to all customers, which cultivated loyal customers and spread all over the world. Now, Uber has the largest market share in the sharing economy market, as it positioned itself across the world. Because of the features of Uber, the company has low operation costs and fixed equipment investments, which reflects on customers at a lower price than the taxi. With above strengths, Uber has some opportunities to gain more market share by developing some new markets and encourage electric or hybrid vehicle, and driver-less-car initiative, which has already begun at the time of the case study. The products and services are more diversified currently. Besides Ride, Drive, and Eat, Uber also diversified products into Freight and Health Market. The ongoing program of Uber is Air, which is expecting to change urban mobility in the future.

\section{Market Weaknesses}

The legality of Uber was being questioned all the time. Because of the unique service features, the services of Uber provided are hard to define and classify, which makes industry specifications and standers unclear. These unclear and uncertain are the reasons why that controversy of Uber never stopped and even became more intense. For the same reason, Uber has low market barriers to entry, high variable costs, and low economic scales with rivals; Uber implied cost leader strategy in the past by offering coupons and bonuses. Additionally, the financial report of Uber remained deep in red ever since Uber was funded. The compete substantial loss is a negative sign for investors in the capital market. Moreover, multiple scandals such as sexual harassment and targeted attack were reported which resulted in a public safety concern, the resignation of a funder, and harmed public image that Uber is not controlled by itself, but dependent on the workforce instead. At the time of the case, both of the drivers and passengers were revolting from the taxi industry to Uber. However, Uber is facing them churn to other competitors currently due to the higher commission cut collected by Uber and negative public relationships and image.

\section{Solutions and Implementations}

\section{Positive Image From the Perspective of Customers and Users}

Comparing to the taxi industry, the services Uber provided are simpler, more convenience, and more private. Customers are able to make comments about the services they received, which is one of the methods for Uber to build customer relationships to their targeted and potential customers. For Uber's users, Uber drivers, the average hourly earnings of Uber drivers were $\$ 6.29$ higher than taxi drivers due to that taxi drivers are required to pay for operation medallions and other leasing payments in 2015 (Moon, 2015). Under this 
situation, a lot of taxi drivers escaping to Uber were understandable. In sharing economy, Uber gives access to everyone to be a driver at any time and make vehicles available for passengers anywhere.

In addition, Uber established a positive reputation among most consumers because the company brought great convenience and lots of benefits to the public improving their experiences, which together brought a certain amount of devotees and loyal customers. In other words, many customers gave high rates to Uber, just as a journalist commented that Uber had replaced taxi and greatly changed people's life (Moon, 2015). Uber had also constructed a positive image based on supportive drivers and customers.

\section{Diversified and Valuable Services}

In order to turn negative impacts brought by surge pricing policy and multiple scandals, Uber launched Uber $\mathrm{X}$, which is one of the cheaper and more valuable services and allowed the use of non-professional drivers and personal cars, UberBlack for commercial use, UberXL in 2015 of larger and cheaper vehicles for six people, UberSUV, etc. Another noteworthy service is UberPOOL providing sharing rides to passengers in the same routes with a much cheaper rate which soon became a popular service that occupied about half of the rides in San Francisco (Moon, 2015).

At the end of 2016, Uber revolutionized the mobile app to control the surging prices and make pricing policy more transparent. By doing that, passengers were able to have knowledge about different prices of all different services Uber provided before decision making. The new app could also mark the most visited locations and design routines according to that.

\section{Using Public Relations to Mitigate Market Aggression}

Uber conducted public relations for its high pricing strategy. It guaranteed people that the charge would be lower than 2.8x in rush hours, and apologized and compensated the surcharges $4 \mathrm{x}$ for passengers in the 2014 Sydney hostage crisis.

In the same year, Uber employed David Plouffe, a well-known political strategist to fugle public relations management and communication functions for the company in order to promote products from a political perspective.

\section{Acquisitions and Self-Driving Car}

The Chinese market of Uber was acquired by Didi Chuxing, who was the biggest competitor in the Chinese market in 2016, which made Uber become the biggest shareholder of Didi Chuxing. This acquisition not only cut off losses due to the price war in the past two years, but it also allowed the company to concentrate on other market segments (Wirtz \& Tang, 2016). Didi Chuxing now has the largest market share in the Chinese market and even raises doubts about industry monopoly. Additionally, Uber has begun the unmanned driving test and auto-pilot in 2016, which was expecting to reduce traffic accidents, cutting congestion and saving spaces.

\section{Sharing Economy for Chinese Enterprise}

The growth of the sharing economy in China was faster than expected in the past 10 years. The particular economic and social situation created the base of the sharing economy development in China. Products and concepts like shared bicycle, shared charging treasure, and shared vehicle were putting onto the market and accepted by the public. The relatively good basic moral literacy and the conditions of dense population density have allowed the sharing economy to grow rapidly in China. Another condition is that productivity is 
developed with uneven distribution. The sharing economy not only solves the problem of over-production of resources but also allocates resources to those in need through the medium of sharing the platform. The nature of the sharing economy is demanding match. The most important point is that China is popular with collectivism and is keener to share. It is easy to accept such products that are shared with others. The growth rate of enterprises that were built upon the concepts on sharing economy in China was much faster than before because of the switch from PC Internet era to mobile Internet base, which is conducive to business development but also a huge obstacle.

After 2016, the depression of the sharing economy came to the market all of a sudden. The reasons for the depression are complicated, including capital flight, the vicious cycle of cash flow, embezzling and failure of management control. According to the data from Tencent, at the end of October 2015, the number of bicycles produced by ofo, which is a bicycle sharing company in China, was only 20,000, and this number had rapidly climbed to 23 million by 2017. Behind the frenzied expansion is the financing recourses delivered by investors. In 2016, there were more than 20 sharing bicycle companies existing in the market at the same time. The total financing of these companies exceeded three billion yuan within one year. The scale of users has also grown exponentially. In 2016, the number of users sharing bicycles reached 18.9 million, an increase of $700 \%$ year-on-year. Only one year later, more companies joined the failure of ofo, with very similar reasons including capital chain fracture, inappropriate operating, cash flow break without now financing resources.

After experiencing explosive growth in the early stage in China, various types of sharing companies have experienced different levels of operational difficulties. Problems such as the difficulty of refunding some corporate deposits have gradually emerged. After the exit of capital investments, the biggest issue of sharing companies in China is finding alternatives to fill the gap. Because of the small market capacity and heavy capital input early, most of the sharing companies in China are experiencing depression. In the long run, sharing companies need to return to the correct business model and track.

\section{Conclusion}

At the time of the case study, Uber was considered as a successful company with controversial. After five years of operations, Uber was valued by investors at $\$ 51$ billion, who was more valuable than the two third of the Fortune 500 (Griffith, 2014). However, Uber is facing a more serious market environment and company situation at this time. The business development did not match with the expectations in Asian, especially Chinese and India market. Meanwhile, the ambiguities of political and regulation legality brought disputable arguments and influences to the company, which consequently impact the public relations and customer relationship.

Even with all of the controversies and competitors, it cannot be denied that the funding of Uber changed trip mode all over the world and it still is an active company in the market with high smartphone app download times and rate. The new services Uber are experiencing like Uber Health and Uber Air to point out the future are possible directions for the company.

As an emerging market, the sharing economy is still facing many challenges, which are similar with Uber, including inadaptability of laws and regulations, urgent need to establish a statistical monitoring system, and protection of customers' rights. Besides the above, from the perspective of entrepreneurs, the understanding of the operations and rules in the capital market becomes more valuable. Although some sharing companies are experiencing depression in China, the general development trend of sharing economy is still believed to be 
potential and bright. With the rapid advancement of mobile Internet, the sharing economy in China is expected to maintain an average annual growth rate of more than $30 \%$ in the next five years (Economic Daily, 2018).

\section{References}

Angrist, J., Caldwell, S., \& Hall, J. (2017). Uber vs. taxi: A driver's eye view. National Bureau of Economic Research.

Chen, M. K., \& Sheldon, M. (Dec. 2015). Dynamic pricing in a labor market: Surge pricing and flexible work on the Uber platform. ACM Conference on Economics \& Computation. Portland, Oregon, United States.

Damodaran, A. (June 2014). A disruptive cab ride to riches: The Uber payoff. Forbes.

Economic Daily. (2018). Chinese annual report on sharing economic development. National Information Center.

Griffith, E. (2014). Uber is now more valuable than at least $72 \%$ of the Fortune 500. Fortune.

Iqbal, M. (May 2019). Uber revenue and usage statics (2019). Business of APP.

Moon, Y. (2015). Uber: Changing the way the world moves. Harvard Business School, Case, 316-101.

Uber. (2019). Retrieved from https://www.uber.com

Wirtz, J., \& Tang, C. (March 2016). Uber: Competing as market leader in the U.S. versus being a distant second in China. In J. Wirtz and C. Lovelock (Eds.), Services marketing: People, technology, strategy (pp. 626-632). Singapore: World Scientific. 